\title{
A Preliminary Study of English Movie Title Translation
}

\author{
Rongmei Yu \\ Nanchang Normal University, China
}

\begin{abstract}
As an important medium for cultural exchange, film has been attracting every nation's attention and thus plays a significant role in cultural exchange. Therefore, the translation of films, with the translating of the titles as the key, is viewed as a direct and easy way of introducing the foreign culture as well as spreading the national culture. A good translated film title not only makes the film more charming but also has its own specific features. The paper first analyses the two primary elements: cultural and language element and nonverbal element, which influence the translation of the film title. Then it presents some main theories on the translation of the film title. Finally it concludes several common methods of translating film titles by abundant examples, which include: literal translation, transliteration, free translation and so on. And this author believes that the phenomenon of one title with several translating versions is acceptable as long as they gain the audiences' satisfaction, the producer's agreement and the government's approval.
\end{abstract}

Index Terms — film titles, theoretical basis, literal translation, transliteration, free translation

\section{INTRODUCTION}

In addition to the superb acting actors, philosophical dialogues and glorious pictures, with its poignant, the reason that a good movie attracts the tens of thousands of audiences lies in the attraction of the title. The film's titles are the brands or the trademarks of the films, because they provide information about the film for the audience by summarizing the central idea, revealing the theme, or offering some clue. A film's title is compared to the lintel of the movie. It must not only reflect the movie's central thought, but also must be brief, novel, and attractive. It is also likened to human eyes that reveal the individual personality, not only prominent, but also very lively, prompting imagination at first glance. In multitudinous film and television advertisement posters, the film's title is in the extremely striking position, to incite the interest to see the film itself.

\section{Elements Determining the TransLation OF Movie TitLES}

\section{A. Language and Cultural Elements}

Each nationality's life style and the thinking mode have similarities as well as discrepancies. People may often peep at the nation's culture spirit and its special characteristics through its language structure, the glossary and the origin of the phrase. Here has the influence which the material environment brings, also existence of some restrictions brought by the social tradition custom practiced thousands of years ago and some other factors. Carefully examines from the angle of translation, the request of the translation is to manifest the cultural connotation which is included in the original text, in order to make the reader can think of something similar to psychological schema or inspired something. If the translation can make readers think of something associate to the turn of the past and the reality, the evolution of time and space and get the life philosophy and the life general knowledge for human's inspiration, then further to understand national characters and relations in the characters of the common human nature, at last the purpose of cultural exchange has been achieved, and the value of translation is in realization. So when we translate film's titles, we should pay attention to the language and cultural elements.

1. Translation is Based on the Understanding of The Source Language

Even if a Chinese phrase and an English word have similar forms, they sometimes refer to different contents, carrying different connotations. For example: A famous psychology trembling film with fear "seven"七宗罪 (qi-zong-zui) in 1995. This movie narrated the crime story which is extremely rich in philosophy thoughts by the impact of intense visual and the gloomy background: A crazy murderer considers himself as God, killing people on the ground of the seven capital punishments of the Catholic. These seven capital crimes refer to seven common errors committed by people, which are: Gluttony, Greed, Sloth, Lust, Pride, Envy and Wrath. Seven is an extremely mystical number in the religion, which finds the fullest expression in The Old Testament: God spent seven days creating Adam, took out Adam's seventh rib to make Eve; the original body of Satan was a fiery dragon with seven heads. The number "seven" recurs time and again in this movie: seven crimes, seven punishments, seven rains. The story took place in seven days, Even the end was decided by the criminal in the seventh day at seven in the afternoon. The ubiquitous "7" suggests the inevitable fate of the crime. If Seven is simply rendered into "七"(qi), the Chinese audience will be surely be bewildered. Therefore the movie's title is specified into 七宗罪 (qi-zong-zui) which points out the main idea of the story and the 
main implications of “seven” in religion. For another example is Devil's Advocate 魔鬼代言人(mo-gui-dai-yuan-ren). The original meaning of Advocate is: people who is for or supports someone's thought, cause or the benefit, such as a defense attorney in the court. This is a phrase originates in the Roman Catholic Church. In history, there have been many persons of high moral character and of holy behavior, their impregnable behavior and the unwavering faith entitled them the names of saints or sages. But it is not an easy thing for anyone to obtain this title, because he must pass through several years of investigation when the Church makes every effort to appoint a priest or other clergy to tap whether the candidates have any slight defect to deprive them of the names. And this investigator is called Devil's Advocate. Because as illustrated in the film there is not an investigator who is nitpick, but the Alpacino is the Satan, so his investigator was Devil's Advocate.

\section{Movie Titles Contain Rich Cultural Information}

Film's titles imply plenty of culture information and emotion, especially when they are idioms or literary quotations which include rich culture information, Often we cannot understand it through literal meaning of the word. For instance, "Rambo: First Blood" is always translated as "第一滴血"(di-yi-di-xue), but one has never realized that "The First Blood" is an English idiom which means "首战告捷(shou-zhan-gao-jie)". Another example is the film Ken Kesey adapted from an autobiographical novel with the same title published in 1962. It is an description of mental hospital that brutally devastates human nature and the basic human rights of the patient. In the movie Indians bravely ran out the iron windows of the prison guard, breaking all shackles and fleeing to a new life. "One Flew over the cuckoo's Nest" has been translated into 飞越杜鹃窝 (fei-ye-du-juan-wo) while in fact "cuckoo's Nest" in English means "a madhouse". So the rendering of 飞越疯人院 (fei-ye-feng-ren-yuan) is more accurate and vivid manifestation of the true meaning of the original film's title and the true meaning of the movie. For another example: the movie Dragon Heart has not been literally translated into 龙的心(long-di-xin). Due to the negative association of the dragon in English with cruelty and devil, rather than Chinese association of prestige or even the king, the translation 魔龙传奇 (mo-long-chuan-qi) is more acceptable.

Due to cultural differences between the SL and the TL, some English movie titles will inevitably contain something peculiar to its own culture. Some mistranslations are caused by misunderstanding of cultural information in original titles. Therefore the translator should be aware of such cultural information, fully understand it, and properly translate it into the TL, to the understanding of the target audience.

\section{Translation is Restrained by the Culture of the Target Language}

Translation is not only a simple language conversion, but also the exchanges of social and cultural between the two countries. A forehead 2.1.1 and 2.1.2 we talked about the restriction of the source language to the target language. At the same time, the translation of the film's title is restrained by the culture of the target language. The culture of the target language will inevitably choose to standardize and strengthen, exclusion, and additional self-culture to the culture of the source language. For instance: "First Wives Club", the phrase "First Wives" in English means to gentleman's First Lady, but China's ancient culture actually had the concept of the big wife and some other wivies, many Chinese thought the film's title should be translated literally as 大老婆俱乐部(da-lao-po-ju-le-bu), but what the movie narrated was how a group of wivies revenge their husbands who abandoned them and made them to get out of the joy of the marries. It should be translated into 发妻俱乐部(fa-qi-ju-le-bu) with more Chinese culture colour. For another example, one of hundred classical American films named "The third man". In China "第三者" (di-san-zhe) is a word related to marital ethics, if the film title is translated into"第三者" (di-san-zhe), the Chinese audience will mistake it be a marital and ethics film. But in fact "The third man" in this movie refers to the third witness of a traffic accident, therefore the translating of 第三个人(di-san-ge-ren)" is more appropriate for Chinese to avoid misunderstanding. Moreover, the movie's titles "Love with My Father" and "The Wedding Night" are translated in Chinese as 天伦乐(tian-lun-le) and 洞 房花烛夜(dong-fang-hua-zhu-ye) respectively, which shows the respect for the Chinese culture.

\section{Language is Changing with the Times}

Languages are the organisms which grow unceasingly, can change along with the social culture development. On the one hand is tendency of preference of spoken language, such as "Much Ado About Nothing" which was previously translated as 庸人自扰(yong-ren-zi-rao) but now 都是男人惹的祸 (dou-shi-nan-ren-re-de-huo), "The Portrait of a Lady" with the previous rendering of 仕女图 (shi-nv-tu) but now 伴我一世情 (ban-wo-yi-shi-qing). On the other hand is a combination of Chinese and English in the translating of English movie titles. For example: "Trueman show" is translated into "真 人(zhen-ren) Show".

\section{B. Nonverbal Elements}

\section{Function of Commercial or Advertisement of the Movie Titles.}

The film's title generally meets the audience before the movie open to play in the theater. A good title leaves profound impression on the audience, stimulating the audience's strong desire for viewing. Without doubt the film's title acts as an advertisement for the movie. In the traditional translation theory: the translation of the film's title belongs to the text translation, actually it is a mistake. The translation of the film's title should be the advertisement translation. There are two reasons: (1) "Film is a visual art, which is unlike other categories of art works. It can not, like books, 
newspapers, display on the desk for exhibition .However, what often first attracts the audience is the film's title "(He Ning, 1,998p 37) the movie title is the movie's trademark and the advertisement. (2)Movie is a synthesis art, its cost is the highest in all of the artistic works. If we shoot a good film, it needs millions and millions, or even Billions of dollars for shooting funds, let alone the pay going to the actors and the actresses. The of photography equipment and high-tech means, that is, the cost of film developing isn't generally affordable for the average people. An author writes a novel at virtually no financial cost. Therefore he does not have to worry so much even if his novel does sell well. But if a movie maker cannot sell out enough copies, then he will suffer bankruptcy, therefore the movie producers must take into account the demand and the prospect of the market. Since the movie producer is undertaking the complete risk, not only should he carry out close investigations and verification before the shooting of the movie, but an attractive title is also necessary. Before the movie's debut, each department for selling the film surely carries on the large-scale propaganda activities. For the movie that brought from abroad, the film's title is the movie's trademark, it plays an important role in the success or failure of the movie. Thus the success of the translation, to a large extent, can be measured by how well it meets such expectations. The translation principles of being faithful to the original author and taking into consideration the trustee's benefit of the work, are the entirely different manners. They may agree with each other but it is also possible that they have quite big conflict.

\section{The Stipulations of the Movie Publication Bureau to the Translation of the Movie Titles}

Because the social system is different or influences of other political factors, each country may interfere in the translation of the film's title may be disturbed, for example the movie made in Hong Kong 黑社会(hei-she-hui) changes its name in the mainland as 龙城社会(long-cheng-she-hui).

\section{Main THEORIES ON THE TransLation OF THE MOVIE TitLeS}

Determined by the above two main factors on the translation of the movie titles, we should stick to the following theories in the translation process

\section{A. Nida's Function Coordinated Theory}

The so-called function coordinated theory is enables the audience in target language to have same felling when accepting the information to produce same feeling as the source language audience has. In the translation, focusing on the translation of the meaning and spirit of the original film instead of the corresponding form. Taking the translation of the film's titles True Lies for example: the film mainly describes a husband who is a agent for secret work and has to conceal his real profession to his wife and the friends and try to fight with the flagitious crime .The plait use the name of movie True Lies which seems like self-contradict to express how does he complete the mission, for the sake of better work, to conceal his real profession for years, taking a lot of trouble at the presence of his wife to prevent her from worrying about him, and to work hard to protect the wife in the face the crime numerator. In the movie the husband lies to his wife out of the true love for his wife. The original name of the movie is an oxymoron, intriguing the curiosity of the audience. While translated into this:魔鬼大帝 in Chinese, which will make the audience do not know what the movie talk about, actually one may wonder who is 魔鬼大帝?Is a crime in the head of a group, or tactful brave special profession worker? The translated name have no relation with the original movie's name ,which makes the original meaning of the movie all gone, and will also mislead the audience to the wild guess of the film's contents, to mistake the action movie for a bloody demon. This kind of translation lose the informative function ,the esthetic sense function and the function of causes. If the name translated into 真实的谎言(zhen-shi-de-huang-yuan) in Chinese which choose the popular easily understanding phrase. Through the words "true" and "lies" which are seems self-contradict, the name of the movie is novel and special, which not only makes audience impress deeply, but also easily create curiosity. Through the above analysis, the true lies translated for into Chinese like this has already basic realized the function coordinated.when translate the text,the relation between receiver and the translated text should be similar to the relation between the original receiver and the original text. The translation of the movie title not only brings about the agreement between the form and the contents, more important, the function of the original name of the movie and the effect to the audience in original countries tends to equal the function of the translated name of the movie and the effect to the audience in other countries.

\section{B. Odore Savory's Readers Analysis Theory}

Famous British translation theorist Odore Savory presents some brilliant opinions that find no parallels before thus introducing a theoretical viewpoint, The original function of the translation is utility. Its function lies in removing the difficulties which the original text brings to the TL audience because readers does not understand it before. As an influential art, it faces the populace, so the film's title must be translated into both have nice form and good meaning, should be based on the appreciation of the audience, familiar to the audience, in words and the expressions easily accepted by the TL audience. For example: if the movie Notting Hill is translated for 诺丁山(di-nuo-shan), the ordinary audience may assume it as a mountain or as a person's name, which appears to be very cautious and an obscure for one to understand. But when it is flexibly translated into 摘星情缘 (zhai-xing-qing-yuan) the romanticism style of the movie is manifest, and the audience also guess right the general idea of the movie plot: the romance between a 
common person and a star. The movie Bodyguard is of this kind too, which narrates a story that a bodyguard falls in love with his employer and how the bodyguard does his best to rescue the beautiful employer in danger. Translated the film title into 护花倾情 (hu-hua-qin-qing)not only has manifested the hero's status and his work, moreover, it has highlighted the movie's plot and the subject it refer to. Another case in point is the movie Speed translated into 生死时 速(sheng-si-shi-su). The westerner likes pertinent, thus such a name Speed which excites people from the beginning to the end by suspense. Although it is classic, if it is translated into Chinese “速度”it will sound plain and dull. Our Oriental has been extremely different. We use “生 “and “死” those two Chinese characters to describe the mood all through this movie. By joining "时速" to corresponding "speed", the title reminds the people of the thrilling scenes.

\section{Giving Full Play to the Advantages of the Target Language}

Because of the differences in language and culture, the mechanic translating of the movie title or word for word translation would make the vivid image in the film dry and tasteless when translated into the target language. One even risks not being accepted by the target language audiences. So we should bring into full play the advantages of the target language, employing the most beautiful and suitable language, and translate the original title into its the closest natural equivalent. Professor $\mathrm{Xu}$ Yuanchong established a new school in a book entitled "On Translation Art" published in 1984, according to his new translation viewpoint, we should be faithful to the original text's content, bring into full play of the target language may be the standards of the literature translation . (Xu Yuanchong 1984), The translator might as well ignore the merits of the target language, but giving full play to the merits of the TL results in a better translation. In other words, though the translated text and the original one are not very similar or each other in form, the reader of the target language can smoothly gain the same or the similar basic information of the original as the reader of the SL does. The basic information mainly includes the thought, the detailed facts, the condition and atmosphere and so on. This way of translation suits to all types of translations. Therefore, this is also suitable for the movie title translation. For example: The Wizard of Oz is translated into 绿野仙踪(lv-ye-xian-zhong). This originates from Chicago journalist Lei Man Bao Mu's novel, later adapted into a musical play, and a movie version was produced in 1936.The meaning of the word “Oz" is scare and imaginary, an inconceivable strange fairyland. The film title purifies the novel 绿野仙踪 (lv-ye-xian-zhong) which was written by Li baichuan in Qing Dynasty. This book take the deity of the different mark as the main clue, and involves the general mood of society and human sentiment, so the translated title is an extremely appropriate flirt.

\section{Chen Hong Wei's Divisions of the Functions of Movie Titles}

Chen Hong Wei divides the functions of movie titles into three categories. They are informative function, esthetic function and imperative function. Informative function means succinctly conveys to the TL audiences the implication of the original title and the content of the film; the esthetic function implies entertaining the TL audiences with beauty and attraction by the elaborate translated title; the two functions serves the imperative function. Psychologically, human beings are endowed with curiosity, a desire for anything fresh and novel, eager to get acquainted with them and easily influenced by them. The imperative function is to influence the mood of the audiences with an aim of their money through the informative function and the esthetic function. For example everybody is familiar with a Disney animation Lilo Meet Stitch, which tells a little violent thing in outer space. In order to escape penalty in its own star, Stitch crashes on the Earth by mistake, and after it lands on Hawaii it becomes the pet of the question girl Lilo by mistake, Lilo has lost the parents since childhood and laboriously fostered by the elder sister, but the American society want to carry Lilo away from the elder sister, giving unemployment of and inability to bring up Lilo as the reason. On the one hand, the outer space head office dispatches workers to arrest Stitch. Stitch becomes a fugitive and wants to escape captures by any possible means, doing a series of funny things. On the other hand the mistake arising out of chance brings joy to Lilo, and enables the sisters to reunite eventually. If we translated it to 利罗遇上斯蒂奇(li-luo-yu-shang-si-di-qi), it will shed no light on the content of the film. But if it is translated into 星际宝贝(xing-ji-bao-bei)or 小魔星(xioa-mo-xing) it will do better in reflecting the essence of the film hence attract the audience. And like the movie "A Walk in the Clouds" ——云中漫步(yun-zhong-man-bu) which describes the moving love story of a man and a woman in vineyard where permeate the air with the grape flower fragrance, in the movie the vineyard is named "the cloud"“云”, the hero and heroine falling in love stroll in the garden with romantic and rich poetic sentiment. The translated name 云中漫步 (yun-zhong-man-bu) extremely suits the subject of a romantic love in the clouds, not only retaining the meaning of the original film title, but also rich in poetic and artistic flavor, which sparks romantic imagination on the part of the audience.

\section{Several Common Methods of Movie Title Translation}

\section{A. Literal Translation}

Literal translation is exactly used when the foreign film's titles have corresponding words or expressions in Chinese, and the words or expressions are quite exquisite in Chinese, that is ,they are more beautiful and more interesting. In the translation of the original film's titles we maintain its content and form. The method of the literal translation we use 
frequently. For example: "A beautiful mind", "Chicken Run", "The love letter", "The Patriot", "Gladiator", "The General's Daughter", “Legends of the Fall”,"Brave Heart “are translated into 美丽心情(mei-li-xin-qing), 小鸡快跑 (xiao-ji-kai-pao), 情书(qing-shu), 爱国者(ai-guo-zhe), 角斗士(jue-dou-shi), 将军的女儿(jiang-jun-de-nv-er), 秋日 的传奇 (qiu-re-de-chuan-qi), 勇敢的心(yong-gan-de-xin); 防守反击(fang-shou-gong-ji), 喜剧之王(xi-ju-zhi-wang), 全职杀手(quan-zhi-sha-shou) are translated into "Defence and Attack", "King of Comedy" and "Fulltime Killer" and so on

\section{B. Transliterate}

Transliterate is a way of writing out the close Chinese characters according to the pronunciation of the words and expressions, we use it very little in the translation of the film's title. Transliteration is the borrowing of the sound of the SL, frequently employed when titles are the place or pe rsonal names, especially when these names are familiar to the target audiences. Like Tarzan, Aladdin which are familiar to children are transliterated separately for 泰山(Tai-shan), 阿拉丁(a-la-ding); Also like Harry Potter 哈利波特(ha-li-bo-te) which was hot in each big movie theater. Others like 芝加哥 (Chicago), 金刚(king kong)(Jin-gang), 伊丽莎白(Elizabeth)(yi-li-sha-bai), 简爱(Jane Eyre)(jian-ai) 卡萨布 兰卡(Casablanca)(ka-sa-bu-lan-ka)and so on

\section{Free Translation}

Free translation is a way of choosing the words and expressions of the target language freely, so long as the translation version is based on the meaning of the original title. It does not call for the corresponding word-for-word transformation. For example: If the Disney animation Shrek is translated into 史莱克(shi-lai-ke), the Chinese audience will not be able to understand it, which does not describe the story neatly and thus fail to provide information and attract the audience. But when the translated title is added by the word “怪物” before it, the reference immediately becomes clear. So is a toy story translated into 玩具总动员(wan-ju-zong-dong-yuan), Forrest Gump into 阿甘正传 (A-gan-zheng-zhuan), Bathing Beauty translated into 出水芙蓉(chu-shui-fu-rong) and so on. For other examples, It Happened One Night, Entrapment, Blood and Sand, The Independent Day are respectively translated into 一夜风流 (yi-ye-feng-liu), 将计就计(jiang-ji-jiu-ji), 碧血黄沙 (bi-xie-huang-sha)and 独立日烽火 (du-li-ri-feng-huo).

\section{Providing a New Title}

This method is a way to get rid of the original film title completely, in fact, to recreate a new name for the movie. For example, film OliverTwist takes the hero's name for the original film title, narrates a London orphan's bitter experience. The translated name 雾都孤儿(wu-du-gu-er) factually and accurately describe the story. Frank and Jesse, icons, Jumanji, Belphorgor (Belphorgor is a mummy's name which was displayed in the Louvre) respectively translated into 乱世双雄 (luan-shi-shuang-xiong), 真假公主 (zhen-jia-gong-zhu), 勇敢者的游戏 (yong-gan-zhe-de-you-xi)and 罗浮魅影 (luo-fu-mei-ying). And“大白纁(Jaws)(sa-bai-sha)”, “怒海争风(Master and Commander)(nu-hai-zheng-feng)” are the examples of this kind.

\section{E. Combination of the Translating Techniques}

Language in movie titles is creatively used. Certainly there are titles to which the four techniques above are not applicable. The combination of certain techniques is required. For instance, literal translation and free translation are often unified. Some cases in point are the Chinese translation of Ghost into 人鬼情未了(ren-gui-qing-wei-lai), in which "鬼" the character is the literal translation while "人"and "情未了" is an explication. This film title have fully manifested the lasting love between the hero and heroine. The Waterloo the Bridge 魂短蓝桥(Hun-duan-lan-qiao), in the movie Waterloo Bridge is the place where the hero and heroine meet and later part, reminding people of the Waterloo where Napoleon was defeated. In order to avoid the ambiguity, the translator uses the literal translation to the bridge to carry on the retention, discards the easily misunderstood word "Waterloo", according to its content, accommodating the folklore the blue bridge meeting, in addition "惊魂(jing-hun)" those two characters which both retain the fundamental mode of the old name, and appropriately expressed the original content, at the same time has avoided the ambiguity. For other examples: Batman 蝙蝠侠(bian-fu-xia)"and Spiderman 蜘蛛侠(zhi-zhu-xia). The literal translation and transliterates are unified:" Kills Bill 杀死比尔(sha-si-bi-er)”. Transliterate and Free translation , such as: Congo, Robin Hood, Casper, Babe are translated into 刚果惊魂(gang-guo-jing-hun), 侠道罗宾汉 (xia-dao-luo-bing-han), 小鬼卡斯(xiao-gui-ka-si) and 小猪贝贝(xiao-zhu-bei-bei). Yet “(Death on the Nile) 尼罗河 上的惨案(ni-luo-he-shang-de-chan-an)" is the combination of the literal translation, transliterates and the method of translating it to another name.

\section{CONCLUSION}

The standard of translation is indeed decided by the different materials for translation. The functional translation theory holds that, each kind of styles has functions of its own. The translation of the film's title as a kind of the 
advertisement translation, its function of translation or the purpose lies in attracting the audience of the target language to spend money on it. The movie will continue to enjoy a high popularity both as an important media of cultural exchanges and as a modern commodity. During the translation of English movie titles, in order to achieve an equivalent effect, the translator should always bear in mind principles of faithfulness, cultural awareness, and combination of commercial and aesthetic effects, and employ techniques appropriate to different titles. Only by doing so, will the titles fulfil their functions. So long as the translation of the film's title makes the audience to be satisfied, the film executive approves, the government agrees, various kinds of the translated names are acceptable.

\section{REFERENCES}

[1] Bao Huinan. (2001). Cultural Context and Language Translation. Beijing: China Translation \& Publishing Corporation.

[2] Chen Hongwei. (2009). New Practical Chinese-English Translation Course. Wuhan: Hubei Education Press.

[3] Jin Di, Nida,Eugene A. (1984). On Translation with special reference to Chinese and English. Beijing: China foreign translation publish company.

[4] Jin huikang. (2003). Intercultural Communicative Translation. Beijing: China Translation \& Publishing Corporation.

[5] Nida, Eugene A. (1993). Language Culture and Translation. Shanghai: Shanghai Foreign Language Education Press.

[6] Nida, Eugene A. \& Charles R. Taber. (1982). The Theory and Practice of Translation. E.J.Bill: Leiden.

[7] Tan zaixi. (2001). New Edition of Nida on Translation.. Beijing: China Translation \& Publishing Corporation.

Rongmei Yu was born in Jiangxi province China in 1964. She received his Bachelor's degree in English Language and Literature from Jiangxi Normal University, China in 1989.

She is currently a professor in Nan Chang Normal University, Jiangxi, China. Her research interests include Intercultural Communication and English Teaching.

Prof. Yu is a member of Jiangxi Translation Association and the teacher of Nan Chang Normal University. 